\title{
VAlidation of Three SETSWANA MEASURES FOR PSYCHOLOGICAL WELLBEING
}

\section{Authors:}

Marié P. Wissing

Sammy M. Thekiso

Ronel Stapelberg ${ }^{1}$

Leanda van Quickelberge ${ }^{1}$

Pinky Choabi ${ }^{1}$

Christine Moroeng

Alida Nienaber ${ }^{1}$

Q. Michael Temane

Hester H. Vorster ${ }^{2}$

\section{Affiliations:}

${ }^{1}$ School for Psychosocial

Behavioural Sciences,

North-West University

Potchefstroom Campus,

South Africa

${ }^{2}$ Centre of Excellence in

Nutrition, North-West

University, Potchefstroom

Campus, South Africa

\section{Correspondence to:}

Marié Wissing

email:

Marie.Wissing@nwu.ac.za

\section{Postal address:}

School for Psychosocial

Behavioural Sciences,

North-West University

(Potchefstroom Campus),

Private Bag X6001,

Potchefstroom, 2520,

South Africa

\section{Keywords:}

psychometric properties;

Setswana; sense of

coherence; satisfaction

with life; affectometer

\section{Dates:}

Received: 22 Aug. 2009

Accepted: 19 May 2010

Published: 06 Dec. 2010

How to cite this article: Wissing, M.P., Thekiso,

S.M., Stapelberg, R., Van

Quickelberge, L., Choabi,

P., Moroeng, C., et al.

(2010). Validation of three

Setswana measures for

psychological wellbeing.

$S A$ Journal of Industrial

Psychology/SA Tydskrif vir

Bedrufsielkunde, 36(2), Art.

\#860, 8 pages. DOI: 10.4102/

sajip.v36i2.860

\section{This article is available}

at:

http://www.sajip.co.za

\section{ABSTRACT}

Orientation: From the perspective of positive psychology, it is important to evaluate people's strengths. There is, however, a lack of validated measures for these purposes in many of the South African official languages. As language is a medium for cultural meanings, measures of mental health should be validated in the mother tongue of the people involved.

Research purpose: The aim of this study was therefore to explore the psychometric properties of Setswana versions of three measures of psychological wellbeing, namely the Sense of Coherence Scale (SOC) (the 29-item version) (Antonovsky, 1987), Satisfaction With Life Scale (SWLS) (Diener, Emmons, Larson \& Griffen, 1985) and Affectometer 2 (AFM) (Kammann \& Flett, 1983).

Research design, approach and method: A cross-sectional survey design was implemented for this study. Questionnaires were translated, back-translated and evaluated in a researchcommittee approach. A stratified sample of 738 Setswana-speaking participants completed the questionnaires in randomly selected sites of the North West province of South Africa as part of the multi-disciplinary Transition and Health during Urbanisation of South Africans project. Reliability indices, means, standard deviations, ranges of scores, patterns of correlations and factor structures were established for all the scales.

Main findings: The present Setswana SWLS and AFM are reliable and valid for use in this group, as is, to some extent, the SOC. The factor structures of the three scales were also consistent with the latent factor structures of the original scales.

Practical implications: These validated measures are instruments for use in the clinical, community and work contexts of Setswana-speaking people.

\section{INTRODUCTION}

In this study, we report on the psychometric properties of three measures of psychological wellbeing that were translated and adapted for use in a Setswana-speaking group, namely the Sense of Coherence Scale (SOC) (the 29-item version) (Antonovsky, 1987, 1993), Satisfaction With Life Scale (SWLS) (Diener et al., 1985; Pavot \& Diener, 1993, 2008) and Affectometer 2 (AFM) (Kammann \& Flett, 1983).

From the perspective of positive psychology or psychofortology (Strümpfer, 1990, 1995, 2006), it is important to evaluate people's strengths and not only their symptoms or what is wrong with them (Lopez \& Snyder, 2003; Seligman \& Csikszentmihalyi, 2000). There is, however, a lack of validated measures for these purposes in some of the South African official languages. As language is an important medium of cultural meanings, it is necessary that measures of mental health should be validated in the mother tongue of the people involved.

Setswana is one of the 11 official languages of South Africa and is used internationally in southern Africa by approximately 4 million speakers. Together with Sesotho and Sepedi, it forms part of the Sotho languages. These languages have much in common and are used by approximately a quarter of the South African population (HSRC, 2009). Setswana is used mainly in the North West province, the Northern Cape and the central and western Free State but also in Botswana, Namibia and Zambia. Sesotho is used mainly in Lesotho, the Free State, southern Gauteng and in the vicinity of Pretoria and Brits; Sepedi is used mainly in Limpopo, Gauteng and Mpumalanga (HSRC, 2009).

The widespread use of Setswana and related languages as a mother tongue in South Africa is therefore evident and the availability of measures for use in community, clinical and work contexts is therefore necessary. These measures should be validated, however, as it cannot be assumed that constructs and the operationalisation thereof that were developed in a Western, more individualistic context are applicable in an African, perhaps more collectivist, cultural context (Biswas-Diener, Vitterso \& Diener, 2005; Christopher \& Hickinbottom, 2008; Floris \& Obasi, 2003; Foxcroft \& Roodt, 2001; Paunonen \& Ashton, 1998; Van de Vijver \& Leung, 1997).

The SOC is based on the model of general resistance resources (GRRs) by Antonovsky (1987). GRRs are psychosocial, material and biological factors that help people to perceive their lives as consistent, structured and understandable. Typical internal and external GRRs are intelligence, ego-identity, commitment, constructive coping behaviour, money, social support, cultural stability, religion and view of life. These resources help people to construct coherent life experiences from which a strong sense of coherence may develop. Sense of coherence is described as a global orientation that expresses the extent to which a person has an enduring but dynamic feeling of confidence that, (1) stimuli deriving from

(c) 2010. The Authors. Licensee: OpenJournals Publishing. This work is licensed under the Creative Commons Attribution License. Note: Permission to translate the Sense of Coherence Scale was provided to the first author by Antonovsky before his untimely death. The Satisfaction With Life Scale (SWLS) and Affectometer 2 are open-source (Diener, http://s.psych.uiuc.edu/ $/$ ediener/hottopic/hottopic. $\mathrm{html}$; Parkinson, 2007). Diener has been provided with a Setswana copy of the SWLS. 
internal and external sources are structured, predictable and explicable, (2) resources are available to meet the demands posed by the stimuli and (3) these demands are challenges worthy of investment and engagement. Core components are comprehensibility, manageability and meaningfulness. A strong sense of coherence has been linked empirically to many positive outcomes, among others, better health (Lindström \& Eriksson, 2006, 2009) and more positive work outcomes (Feldt, Kinnunen \& Mauno, 2000; Kinman, 2008; Van der Colff \& Rothmann, 2009).

Strümpfer (1990) was the first to introduce Antonovsky's concept of sense of coherence in South African research. The model is an example of eudaimonic conceptualisation (Ryan \& Deci, 2001; Waterman, 1993; Waterman, Schwartz \& Conti, 2008) of wellbeing, which is about meaning and positive functioning. The SWLS and AFM are associated with the hedonic approach (Waterman, 1993; Waterman et al., 2008) to psychological wellbeing, in which focus is on positive emotions and happiness.

The SWLS is based on the conceptualisation of subjective wellbeing and happiness by Diener (1984, 1994, 2000). Subjective wellbeing or satisfaction with life is determined cognitively by individuals using their own criteria. Although the SWLS is presented as a global evaluation of life, Heller, Watson and Ilies (2004) have found substantial intra-individual variation in life satisfaction that is linked to domains such as job satisfaction and marital status.

The AFM measures positive and negative emotions as well as the balance between them (Kammann \& Flett, 1983). Positive emotions are hypothesised to be a major component of psychological wellbeing. This perspective links with the broaden-and-build model of positive emotions by Fredrickson (2000, 2001), in which it is hypothesised that, although they are short-lived, positive emotions beget upward spirals. They broaden cognitive horizons and build physical vitality and positive relationships. Strong empirical evidence is provided for Fredrickson's model and its application in many contexts (Cameron, 2008; Fredrickson \& Joiner, 2002; Fredrickson, 2006; Lyubomirsky, 2008; Lyubomirsky, Sheldon \& Schade, 2005).

The choice of the SOC, SWLS and AFM for validation as measures of wellbeing was informed by the fact that they represent both the eudaimonic and the hedonic approaches to psychological wellbeing, that they have generally good psychometric properties in various cultural contexts, that they are frequently used in South Africa and that they have been shown to measure a 'general psychological wellbeing component' (Wissing \& Temane, 2008; Wissing \& Van Eeden, 2002).

In the past, these scales were used in many South African studies and in many different contexts (Cilliers \& Coetzee, 2003; Fourie, Rothmann \& Van de Vijver, 2008; Hamad, Fernald, Karlan \& Zinman, 2008; Rothmann, Steyn \& Mostert, 2005; Strümpfer \& Mlonzi, 2001; Strümpfer, Viviers \& Gouws, 1998; Strümpfer \& Wissing, 1998; Temane \& Wissing, 2006; Westaway, Maritz \& Golele, 2003; Wissing \& Van Eeden, 2002; Wissing, Wissing, Du Toit \& Temane, 2008). Whereas the salutogenic or fortigenic approach and positive psychology were initially viewed as a new academic movement or sub-discipline, they are now increasingly becoming an applied field in community, clinical and work contexts. Many organisations are focusing on developing so-called positive organisations or offer wellnessenhancement services to their employees or clients (Bakker, 2006; Biswas-Diener, 2009; Cameron, 2008; Cameron, Dutton \& Quinn, 2003; Fourie et al., 2008; Linley \& Joseph, 2004; Luthans, Luthans \& Luthans, 2004; Schaufeli, 2006; Turner, Barling \& Zacharatos, 2002).

Most of the previous South African studies, however, were conducted with the English versions of these scales and mostly only with participants from urban areas. The question is therefore to what degree the SOC, SWLS and AFM can be refined and adapted for culture-sensitive use in a Setswana-speaking group from both urban and rural areas and whether their psychometric properties would be relatively invariant when compared to the previous findings for the English version and in other cultural groups. According to Paunonen and Ashton (1998), invariance in the following psychometric properties may reflect cross-cultural applicability: (1) scale means and variances, (2) reliabilities, (3) factor structures and (4) patterns of correlations with other variables (criterion-related validity and convergent and discriminant validity). Measures of psychological wellbeing, such as the SOC, SWLS and the positive affect (PA) sub-scale of the AFM would be expected to correlate positively with each other and negatively with the negative affect (NA) sub-scale of the AFM.

The aim of this study is therefore to determine the reliability and validity of scales measuring psychological wellbeing (the SOC, SWLS and AFM) for use in a Setswana-speaking African group.

\section{RESEARCH DESIGN}

\section{Research approach}

This was a quantitative study conducted according to a crosssectional field-survey design. Primary data were used and collected during several field studies in randomly selected sites of the North West province of South Africa as part of the multidisciplinary Transition and Health during Urbanisation of South Africans (THUSA) project. Descriptive, correlational and factor analytical approaches were implemented in the data analysis.

\section{Research method \\ Participants}

Pilot groups: Nine participants were purposely selected from the target group to participate in the preliminary evaluation of selected questionnaires for comprehensibility and response format. After adaptation, a second pilot group $(N=30)$ participated in the preliminary evaluation of the translated measures.

Main group for data gathering: A group of 738 Setswanaspeaking African volunteers, recruited in 10 randomly selected sites in the North West province of South Africa, participated in this study. The participants were stratified for gender (males: $n=313$; females: $n=424)$, age (15-24 years: $n=184 ; 25-34$ years: $n=206$; $35-44$ years: $n=126 ; 45-54$ years: $n=100$; 55 64 years: $n=73$; 65 yearst: $n=48$ ) and level of urbanisation (deep-rural tribal respondents: $n=196$; farm workers: $n=113$; informal settlements: $n=168$; urban township dwellers: $n=250$; professional people: $n=11$ ).

\section{Measures}

Selected questionnaires were evaluated and culture-sensitively adapted in a research-committee approach (Van de Vijver \& Leung, 1997). The measures were translated, back-translated and evaluated (Brislin 1970; Van de Vijver \& Leung, 1997) and then pilot-tested before data gathering.

Demographic questionnaire: Demographic information needed for the whole THUSA project was gathered at the same time. The relevant aspects for this study were gender, age and stratum.

Sense of coherence (Antonovsky, 1987, 1993): The SOC measures the way in which individuals experience the world and their life in it. Core components are comprehensibility, manageability and meaningfulness. The scale consists of 29 items. Antonovsky (1993) has indicated cross-cultural applicability and has reported Cronbach alpha reliabilities from 26 studies ranging from 0.82 to 0.95 . Strümpfer and Wissing (1998) have reported reliability indices ranging from 0.52 to 0.97 , with a mean alpha of 0.87 , from 27 South African studies implementing the English version. Good content, criterion and construct validity have been reported in Western groups by Antonovsky, by Flannery, Perry, Penk and Flannery (1994), by Frenz, Carey and Jorgensen (1993) and by Eriksson and Lindström (2005). 
Affectometer 2 (the short version) (Kammann \& Flett, 1983): The AFM measures general happiness or sense of wellbeing as experienced on an affective or emotional level. The overall level of wellbeing is expressed as the extent to which positive feelings predominate over negative feelings. The sub-scales are PA, NA and positive-negative-affect balance (PNB). The short form of this scale (used in this study) consists of 20 items (10 indicating NA and 10 indicating PA). Kammann and Flett (1983) have reported a Cronbach alpha of 0.88 and indications of validity for Western groups. Cronbach alphas in South African samples, implementing the English version, vary from 0.81 to 0.92 for the long version (Wissing \& Van Eeden, 2002). The short version of the AFM has been found reliable and valid for use and recommended as a measure of emotional wellbeing in the core set of indicators of mental health in Scotland (Parkinson, 2007).

Satisfaction with life scale (Diener et al., 1985): The SWLS measures people's assessment of their quality of life as experienced on a cognitive-judgmental level. It consists of five items. Cronbach alpha reliabilities vary between 0.79 and 0.89 in Western samples (Pavot \& Diener, 1993) and between 0.84 and 0.79 in a multi-cultural South African sample (Wissing \& Van Eeden, 2002) with the implementation of the English version. Pavot and Diener $(1993,2008)$ have reported extensively on the construct validity and cross-cultural applicability of the SWLS.

\section{Procedure}

The procedure of the THUSA project has been described in detail elsewhere (Vorster et al., 2000). Guidelines for culture-sensitive research have been taken into consideration through the whole process, as indicated by, among others, Rogler (1989), Smith and McCarthy (1995) and Paunonen and Ashton (1998). The Ethics Committee of the University approved the THUSA study (approval No. 4M5-95). The following are the main processes as far as this study is concerned.

Preparation of scales: This included the selection and then the preliminary evaluation of the scales with the aid of a pilot group from the target population to determine the comprehensibility, the cultural appropriateness of words and phrases and the technical aspects of questionnaire completion. The first six authors of this article - three of whom are Setswana mothertongue speakers and psychologists - formed the research committee for the evaluation of the translations.

The evaluation of the English back-translation of the Setswana SOC showed some minor changes in wording for Items 3,10 , $12,19,25$ and 29. The research committee found that the original meaning was retained in five of these items, except for slight modifications for Items 3 and 25.

For Item 3, 'Think of people with whom you come into contact', with the anchors on the 7-point rating scale, 'You feel that they're strangers' and 'You know them very well', the back-translation was 'Remember the people you always meet (not those you feel you are near them). How do you know them?'

The original English version of Item 25 was 'Many people even those with a strong character - sometimes feel like sad sacks (losers) in certain situations. How often have you felt this way in the past?', with the anchors of 'Never' and 'Very often'. The back-translation was 'Many people feel sometimes that they are left behind (are losers), how many times did you feel like this?', thereby omitting the part 'even those with a strong character' and the expression 'sad sacks'. The arguments for this were that the sentence should be simplified and that Setswana culture is more collectivistic, not emphasising individualistic characteristics as strongly as is the case in the Western cultural context. The expression 'left behind' is more culturally sensitive. In the case of Item 29, the research committee found a slight modification in meaning in the back-translation. The original English item was 'How often do you have feelings that you're not sure you can keep under control?', with the literal backtranslation being 'How often has it been that you have felt that you were unable to control things in your life?' The original item therefore focuses more on emotion as an intra-psychological phenomenon and the back-translation on 'things in your life', which could refer either to internal or to external things. As this item is supposed to measure manageability and as cultural focus is less on intra-psychological facets and more on life in context, the research committee decided to accept the Setswana item, as translated.

In the case of the AFM, no meaning differences between the original and the back-translated English version were identified, although slight differences in wording did occur. In the case of Item 14, a more culture-sensitive idiom was used. The original 'my life is stuck in a rut' was back-translated as 'my life seems roped up/attached to ropes', which was a correct direct translation of the Setswana and which the research committee agreed should be retained.

The back-translated English version of the SWLS revealed no meaning differences, although the wording for Items 1, 2 and 5 were slightly different. The original Item 5 , for example, was 'If I could live my life over, I would change almost nothing' and the back-translation was 'If I were to live my life again, I wouldn't change a thing'.

On the grounds of comments from the pilot group, the response sheets were also adapted to be more user-friendly. A 2-phase response format was introduced for the SOC, with a 7-point scale, which proved difficult for some of the participants in the pilot group. In the new method of administration, the participants firstly evaluated, per item, whether their answers were more to the one (1) or to the other (7) anchor point of the 7-point continuum and, secondly, step-evaluated which rating in that section fit best. The questionnaires were then again pilottested on participants from Stratum 3.

Preparation for fieldwork: This included obtaining approval from the Department of Health of the North West province (negotiated by Prof H.H. Vorster as the THUSA project leader), randomly selecting sites, obtaining permission to conduct the study from the relevant authorities at a particular site (a tribal chief, community leaders, the headmasters of schools, employers mayors etc.) and informing the community about the study in a meeting arranged with the assistance of a local person and again, by way of a leaflet, a week before data gathering. In this phase, the fieldworkers were also trained in the administration of the questionnaires. In some sites, local fieldworkers were trained, whereas already trained fieldworkers collaborated in other sites.

Data gathering: During the data-gathering phase, volunteers were recruited in selected sites from 1998 to 2000. After their informed consent was obtained, the questionnaires were administered with the aid of fieldworkers in small groups for literate people and in structured-interview format for illiterate people. Facilities for testing ranged from community halls, clinics and schools, to verandas and the shade of trees.

\section{Statistical analyses}

Descriptive statistics for the measures were determined, as were Cronbach alpha-reliability indices. For the purposes of this study, reliability coefficients higher than 0.70 were considered as acceptable, those between 0.60 and 0.69 as modest and those below 0.60 as unacceptable. Internal consistency or the homogeneity of scales was also judged by average inter-item correlations and item-total correlations. Clark and Watson (1995) have recommended a guideline of 0.15 to 0.50 for such correlations, with a norm of 0.15 to 0.20 for broad constructs and 0.40 to 0.50 for narrower constructs. For the purposes of this study, the general guideline of 0.15 to 0.50 was used.

Concurrent validity was determined by establishing correlational patterns among scales, in which case it was expected that the SOC, AFM:PA and SWLS would correlate positively with each other and negatively with the AFM:NA. To determine construct 
TABLE 1

Means, variances and reliability indices for scales measuring psychological wellbeing $(N=738)$

\begin{tabular}{|c|c|c|c|c|c|c|c|}
\hline \multirow[t]{2}{*}{ Sub-scales } & \multirow[t]{2}{*}{ Mean } & \multirow[t]{2}{*}{$S D$} & \multicolumn{2}{|c|}{ Range } & \multirow[t]{2}{*}{$\alpha$} & \multirow[t]{2}{*}{ Range of item-total correl. } & \multirow[t]{2}{*}{ Mean inter-item correl. } \\
\hline & & & Min. & Max. & & & \\
\hline Sense of coherence & 121.86 & 20.2 & 64 & 197 & 0.70 & $0.07-0.41$ & 0.07 \\
\hline Satisfaction with life scale & 22.27 & 6.03 & 5 & 35 & 0.67 & $0.22-0.52$ & 0.29 \\
\hline Positive affect & 36.04 & 6.48 & 14 & 50 & 0.68 & $0.26-0.44$ & 0.18 \\
\hline Negative affect & 27.42 & 8.35 & 10 & 48 & 0.77 & $0.24-0.57$ & 0.28 \\
\hline
\end{tabular}

$S D$, standard deviation; $\alpha$, Cronbach alpha value

validity, evaluations were done by testing structural equation models (the confirmatory option) with the aid of SEPATH (Statsoft Inc., 2004). The root mean square error of approximation (RMSEA), goodness of fit index (GFI) and adjusted goodness of fit index (AGFI) were reported as measures of fit. Criteria for the point estimates of an acceptable fit implementing RMSEA varied from 0.05 to 0.08 in literature. Hu and Bentler (1999) have recommended a point-estimate value for RMSEA lower than 0.06. MacCallum, Browne and Sugawara (1996) have viewed RMSEA values of 0.08 to 0.10 as indicating a mediocre fit and those greater than 0.10 as indicative of a poor fit. Vandenberg and Lance (2000) have argued that previous research suggests that a value of .08 for the RMSEA is acceptable. For the purposes of the current validation, it was decided to consider a fit of 0.08 and lower as acceptable. The recommended cut-off for a good fit implementing the GFI and AGFI is 0.9 (Hu \& Bentler, 1999; Marsh, Hau \& Wen, 2004) but debate continues on cut-off values for the evaluation of fit in structural equation models. Traditional principal-component confirmatory factor analyses (CFA) were also performed, which is common practice in measurement. Zwick and Velicer (1986) have indicated that the loadings of items on the hypothesised factors should be 0.3 and higher.

\section{RESULTS}

\section{Means, variances and reliability indices of all scales}

Descriptive statistics and reliability indices for all the scales are presented in Table 1.

The reliability indices obtained for the SOC and AFM:NA were acceptable and those for the SWLS and AFM:PA were modest to acceptable. Inter-item and item-total correlations for the SOC were relatively low but within the norm for the other measures. These reliability indices were in line with those reported by Wissing et al. (2008) for another African group.

\section{Correlations}

The obtained correlations among all the (sub-)scales were in accordance with the hypothesised pattern and supported the concurrent and convergent validity of the scales involved (Table 2).

The indices of psychological wellbeing were positively related to each other, as expected, and the AFM:NA was, as expected, negatively related to positive measures of wellbeing. The fact that the pattern of correlations among these scales was the same as in other (Western) samples may contribute to a conclusion that these scales were cross-culturally valid. Correlations with stratum were very low but, in the case of the SWLS participants in rural areas (deep rural and farms), showed statistically significantly lower scores $(M=21.2, S D=6.4)$ than those from urban areas (informal settlements and townships) ( $M=23.0$, $S D=5.5)$. This difference, however, was only of small practical significance $(d=0.27)$ and both were still in the 'slightly satisfied' category, as distinguished by Pavot and Diener (2008).

\section{Factor structure of scales}

\section{Sense of Coherence Scale}

A confirmatory factor analysis performed with the aid of the SEPATH option of STATISTICA revealed a good (although not perfect) fit of the apriori hypothesis that this scale consisted
TABLE 2

Correlations among all variables $(N=738)$

\begin{tabular}{lllllll}
\hline & PA & NA & PNB & SOC & SWLS & STR \\
\hline Positive affect & - & - & - & - & - & - \\
Negative affect & $-0.16^{*}$ & - & - & - & - & - \\
Positive-negative-affect balance & $0.69^{*}$ & $-0.83^{*}$ & - & - & - & - \\
Sense of coherence & $0.33^{*}$ & $-0.43^{*}$ & $0.50^{*}$ & - & - & - \\
Satisfaction with life scale & $0.41^{*}$ & $-0.09^{*}$ & $0.30^{*}$ & $0.26^{*}$ & - & - \\
Stratum & 0.05 & $-0.08^{*}$ & $0.09^{*}$ & $0.08^{*}$ & $0.14^{*}$ & -
\end{tabular}

PA, positive affect; NA, negative affect; PNB, positive-negative-affect balance; SOC, sense of coherence; SWLS, satisfaction with life scale; STR, stratum. coherence; SWLS, satisfaction with life scale; STR,
All indicated correlations are significant at $p<0.05$

TABLE 3

Indices of fit for all measures

\begin{tabular}{|c|c|c|c|}
\hline Measures & $\begin{array}{l}\text { RMSEA } \\
\text { (90\% confidence interval) }\end{array}$ & GFI & AGFI \\
\hline Sense of coherence & $\begin{array}{l}0.055 \\
(0.051-0.058)\end{array}$ & 0.899 & 0.883 \\
\hline Satisfaction with life scale & $\begin{array}{l}0.035 \\
(0.0-0.069)\end{array}$ & 0.995 & 0.984 \\
\hline Affectometer & $\begin{array}{l}0.052 \\
(0.047-0.057)\end{array}$ & 0.935 & 0.920 \\
\hline
\end{tabular}

RMSEA, root mean square error of approximation; GFI, goodness of fit index; $A G F I$, adjusted goodness of fit index; SOC, sense of coherence; SWLS, satisfaction with life scale; AFM, affectometer 2 .

of one major factor (Antonovsky, 1987, 1993) (Table 3). All the items, except 5 and 20, loaded statistically significantly on the hypothesised latent factor. A 0.055 Steiger-Lind RMSEA index of fit was obtained with a $90 \%$ confidence interval of 0.051 to 0.058. The indices for the GFI and AGFI were also close to 0.90, indicating a modest fit.

A principal-component factor analysis revealed several factors but an inspection of the scree plot clearly indicated the presence of one major factor. This factor had an eigenvalue of 3.43 but explained only $11.8 \%$ of total variance. The factor structure identified was akin to the one hypothesised by Antonovsky (1993). An inspection of the item loadings on this factor showed low contributions from Items 5 (0.08) and 20 (0.07).

As Antonovsky theorised that sense of coherence as a construct consists of three components, namely comprehensibility, manageability and meaningfulness, it was decided to establish whether these components manifested themselves in the present data. To this end, a confirmatory principal-component factor analysis with varimax rotation was performed, requesting three factors. Three factors emerged, with eigenvalues greater than 1.0, explaining 23.82 of total variance. Comprehensibility emerged as a major factor, according to the criteria defined by Zwick and Velicer (1986) (that is, eigenvalues greater than 1.0 and at least 3 significant loadings ( $>0.30$ - from the apriori hypothesised items) but the items of manageability and meaningfulness also loaded significantly on this factor. Factors 2 and 3 indicated a mixed picture, with meaningfulness and manageability both contributing equally strongly. The findings therefore indicated that the three hypothesised components were not separable.

A confirmatory factor analysis performed with the aid of SEPATH, testing Antonovsky's hypothesis of three sub-components, revealed an acceptable fit, with a Steiger-Lind RMSEA index of 0.063 and a $90 \%$ confidence interval of 0.060 to 0.067 . Although 
this seemed to be an acceptable fit, the fitting obtained for one factor was better, as indicated in Table 3 .

These results indicated that the SOC measures a relatively homogeneous construct with three identifiable components but that the total scale score should be used as advised by Antonovsky (1993) and not scores from the separate components.

Two exploratory factor analyses (EFA) supported the abovementioned conclusion. EFA with maximum likelihood and with principal-axis methods of factor extraction both revealed a single factor with both eigenvalues of 2.56 , explaining $8.83 \%$ and $8.8 \%$ of total variance, respectively. An exploratory principalcomponent factor analysis, however, identified 10 factors, with eigenvalues greater than 1.0, explaining $51.57 \%$ of total variance. Although the principal-component method of factor extraction tends to over-extract (Velicer \& Jackson, 1990; Zwick \& Velicer, 1986), these obtained factors explained far more variance than was the case above. Korotov (1994) has also referred to the identification of 10 factors but has not provided further information.

\section{Satisfaction with Life Scale}

A confirmatory factor analysis performed with the aid of SEPATH revealed a highly satisfactory fit of the hypothesised model to the data (Table 3). All the items loaded significantly on one latent factor. A Steiger-Lind RMSEA index of 0.035 (with a $90 \%$ confidence interval of 0.000 to 0.069 ) indicated a good fit and indices higher than 0.90 for the GFI and AGFI supported the fit of the model. The result of a confirmatory principal-component factor analysis supported this finding. All the items loaded between 0.63 and 0.77 on this factor, except Item 5 , for which the loading was 0.38 . This was in line with findings by Oishi (2006) that the fifth item of the SWLS was somewhat distinct from the other items. As this item was still highly correlated with the others and significantly contributed to this factor, however, there was no need for it to be dropped.

EFA with both principal-component and maximum-likelihood methods of factor extraction revealed the same results as the confirmatory factor analysis, attesting to the construct validity of the translated SWLS. The factor structure of the SWLS, in the present group, was therefore invariant from that reported elsewhere.

\section{Affectometer 2}

A confirmatory factor analysis, performed with the use of SEPATH and testing the hypothesis of two latent factors (PA and NA), produced a very good fit of the model to the data: Steiger-Lind RMSEA $=0.052$ (90\% confidence interval 0.047 to 0.057$)$ (Table 3) and indices above 0.90 for the GFI and AGFI. All the items loaded statistically significantly on the latent factors.

A confirmatory principal-component factor analysis also produced two clear factors that can be distinguished as PA and NA. An inspection of the scree plot confirmed this interpretation. The same factor pattern as above emerged in an exploratory-factor analysis, with a maximum likelihood method of factor extraction. The constructs underlying the AFM (as measured here) were therefore just as valid in the present Setswana-speaking group as in the original group.

\section{DISCUSSION}

The aim of this study was to determine the reliability and validity of three translated measures of psychological wellbeing (the SOC, SWLS and AFM) for possible use in a Setswana-speaking group. There is a great need for psychological measures in all the official languages of South Africa, especially for measures of the positive facets of mental health as argued from a fortigenic or positive psychology perspective.

The current translated and refined SWLS and AFM were found to be reliable and valid for use in a Setswana-speaking group, modestly so for the SOC. Further research on the SOC may be valuable. Reliabilities, variances, factor structures and correlation patterns for all three measures are relatively invariant from those reported in the original and other available reference groups with the English version. Mean scores for NA are slightly elevated and mean scores for psychological wellbeing slightly lower than reported for some other groups, although previous studies did not include community samples of this kind. The present study found mean scores may accurately reflect the mental status of this group at the time of data gathering and may be explained by socio-historical conditions.

The Setswana SOC shows an acceptable Cronbach alpha index but inter-item correlations are relatively low and further item refinement can therefore be done in future research, especially taking into account the relatively low loadings of Items 5 and 20 that were found in the validity exploration. The mean score of $121.86(S D=20.2)$ on the SOC is in the mid-range of means, as reported by Antonovsky (1993) for 26 studies (age and context do seem to influence mean scores). This, however, is noticeably lower than the mean score of 137 calculated by Strümpfer and Wissing (1998) for 27 studies conducted in South Africa on a total of 3979 people. These studies, however, were mostly on white, multi-cultural and urban samples. The present obtained SOC score of 121.86 is only slightly higher than that reported by Wissing et al. (2008) for Setswana-speaking students with the English version, namely 119.8 . In a recent systematic review of 124 studies, Eriksson and Lindström (2005) have reported mean scores for the SOC-29 between 100.5 (SD 28.5) and 164.5 (SD 17.1). The current study found that the mean for the Setswana SOC compares well with that of other South African studies using the English version and with international findings.

The SOC manifests concurrent validity and factor analyses support construct validity by confirming the hypothesis of a one-factor solution as the best one, akin to that reported by Antonovsky (1993), but the relatively low percentage of variance explained is a reason for concern. Frenz et al. (1993) and Eriksson and Lindström (2005) have also found that the SOC is multidimensional but have concluded that the best solution obtained for the SOC is for a single factor and that it should be interpreted as such. Although the SOC seems to manifest construct validity for this particular group, further research is necessary. Findings therefore tentatively suggest that the Setswana SOC is reliable and valid for use in the current group and provide some support from an African perspective for Eriksson and Lindström's conclusion that the SOC is reliable, valid, feasible and crossculturally applicable. This, however, is not to say that the SOC is the most optimal measure to evaluate psychological wellbeing in an African context. It may therefore be profitable to develop new measures based on in-depth qualitative research on the conceptualisation and manifestation of psycho-social wellbeing in an African context.

The Setswana AFM has been shown to be an internally consistent two-dimensional measure with concurrent and construct validity. A higher Cronbach alpha was found for NA (0.77) than for PA (0.68) in this study, which is akin to that reported by Wissing et al. (2008) for a Setswana group of students with the English version $(P A=0.64$ and $N A=0.79)$ but lower than that reported by Kammann and Flett (1983). The mean scores for PA (36.04, SD 6.48) and NA (27.42, SD 8.35) are similar to those reported for the English version in a Setswana-speaking student group (PA 37.2, SD 5.2; NA 23.5, SD 7.4) (Wissing et al., 2008) and to those of a group of Afrikaans and English-speaking students for the English version (PA 36.54, SD 5.90; NA 22.33, SD 6.79) (Du Toit, Wissing \& Putter, 2000). The Setswana version of the short form of the AFM can therefore be recommended for use in this group.

The SWLS manifests a modest Cronbach alpha-reliability index (0.67) but good item-total and inter-item correlations, which attest to the homogeneity of the scale. The pattern of a modest Cronbach alpha but good item-total and inter-item correlation 
has been repeatedly found in other South African studies in this community but is lower than that reported for Western groups. Wissing et al. (2008) have reported a 0.66 reliability index in a Setswana-speaking group of students for the English version, whereas the Afrikaans and English-speaking group had an index of 0.85 . Keyes et al. (2008) have reported an index of 0.69 in a large Setswana-community sample $(N=1050)$. In Western groups, Pavot and Diener (1993) have reported Cronbach alphas between 0.79 and 0.89 . The fact that the SWLS seems to perform differently in some respects in an African context has also been shown in secondary factor analyses of measures of wellbeing where the SWLS clusters with variables such as social support and social wellbeing, whereas it clusters in Western samples with indices of intra-psychological wellbeing, such as SOC and PA (Wissing \& Temane, 2008).

The mean score of 22.27 (SD 6.03) for the SWLS found in this study is in the 'slightly satisfied' bracket (21-25), as categorised by Diener (Pavot \& Diener, 2008). A score of 20 represents the neutral point where a person is about equally satisfied and dissatisfied. Wissing et al. (2008) have also reported a mean score in the 'slightly satisfied' bracket for the English version in a Setswana-speaking group (24.2, SD 5.2). Higher mean scores are usually reported in Western and more affluent groups (Arrindell, Heesink \& Feij, 1999; Pavot \& Diener, 2008), where scores of large groups are in the 'satisfied' bracket. The significantly lower SWLS scores manifested in this study by rural participants may therefore also be attributed to their lack of resources. In this study, the Setswana version of the SWLS shows concurrent and construct validity similar to that reported for the English version in other South African studies (Wissing et al., 2008) and to that reported in various Western contexts (Pavot \& Diener, 2008). The Setswana version of the SWLS is therefore valid for use in this group.

It can be concluded that the Setswana versions of the SOC, AFM and SWLS are applicable for use with Setswana-speaking participants but that further research is necessary, especially in the case of the SOC. The relatively lower Cronbach alphas manifested in this study in comparison to others may be attributed partially to the fact that this sample was a stratified community sample including rural and urban areas as well as literate and illiterate people. This may also explain the slightly lower scores on the wellbeing measures and higher score on NA and the relatively poor socio-economic context of these participants and the historical South African situation. Further research should explore the current findings in other groups, establish test-retest reliabilities, perform in-depth item-analysis for the individual scales and explore predictive and discriminant validity.

Some limitations of this study are the cross-sectional nature of the design in the first instance, although it is sufficient for initial validation purposes. Future research could use longitudinal designs, especially when predictions are implied, that could make it possible to examine the stability of these measurements within and across groups to help establish norms for these scales in South Africa. Secondly, the study uses traditional factoranalysis procedures because of comparability with other such studies. Newer techniques combining both CFA and EFA are proposed, such as exploratory structural equation modeling (Asparouhov \& Muthén, 2009), especially because of the untenable problem of acceptable model fit with multi-factor instruments.

The availability of reliable and valid measuring instruments, such as the present Setswana versions of the SOC, AFM and SWLS, can help to provide instruments with a focus on wellbeing and strengths in one of the indigenous South African languages that can be implemented in epidemiological studies and in community, health and work contexts. These scales also provide means through which the impact of (capacity building, coaching and psychotherapeutic) intervention programmes can be evaluated. This is in line with various calls that more attention should be paid to psychological health instead of only pathology and a step in furthering the fortigenic approach as advocated by Strümpfer $(1990,1995,2006)$.

\section{ACKNOWLEDGEMENTS}

This study was financially supported by the National Research Foundation, the Medical Research Council and the then Potchefstroom University for Christian Higher Education, now North-West University: Potchefstroom Campus.

\section{DEDICATION}

This paper is dedicated to Prof Deo Strümpfer as mentor, friend, colleague and honourary member of the Department of Psychology and Psychofortology research group of North-West University, Potchefstroom Campus.

\section{REFERENCES}

Antonovsky, A. (1987). Unravelling the mystery of health: How people manage stress and stay well. San Francisco: Jossey-Bass.

Antonovsky, A. (1993). The structure and properties of the sense of coherence scale. Social Science Medicine, 36(6), 725-733.

Arrindelle, W.A., Heesink, J., \& Feij, J.A. (1999). The satisfaction with life scale (SWLS): Appraisal with 1700 healthy young adults in The Netherlands. Personality and Individual Differences, 26, 815-826.

Asparouhov, T., \& Muthén, B. (2009). Exploratory structural equation modeling. Structural Equation Modeling, 16(3), 397438.

Bakker, A.B. (2006, April). A positive approach of organizational behaviour. Keynote address at the South African Conference on Positive Psychology: Individual, Social and Work Wellness, Potchefstroom.

Biswas-Diener, R. (2009). Personal coaching as a positive intervention. Journal of Clinical Psychology: In Session, 65(5), 544-553.

Biswas-Diener, R., Vitterso, J., \& Diener, E. (2005). Most people are happy, but there is cultural variation: The Inughuit, the Amish, and the Maasai. Journal of Happiness Studies, 6 , 205-226.

Brislin, R.W. (1970). Cross-cultural research methods. New York: John Wiley.

Cameron, K. (2008). Positive leadership: Strategies for extraordinary performance. San Francisco: Berrett-Koehler Publishers.

Cameron, K., Dutton, J.E., \& Quinn, R.E. (2003). Positive organizational scholarship: Foundations of a new discipline. San Francisco: Berrett-Koehler Publishers.

Christopher, J.C., \& Hickinbottom, S. (2008). Positive psychology, ethnocentrism, and the disguised ideology of individualism. Theory and Psychology, 18(5), 563-589.

Cilliers, F., \& Coetzee, S. (2003). The theoretical-empirical fit between three psychological wellness constructs: Sense of coherence, learned resourcefulness and self-actualisation. South African Journal of Labour Relations, 27(1), 4-24.

Clark, L.A., Watson, D. (1995). Constructing validity: Basic issues in objective scale development. Psychological Assessment, 7, 309-319.

Diener, E. (1984). Subjective wellbeing. Psychological Bulletin, 95(3), 542-575.

Diener, E. (1994). Assessing subjective wellbeing: Progress and opportunities. Social Indicators Research, 31, 103-157.

Diener, E. (2000). Subjective wellbeing: The science of happiness and a proposal for a national index. American Psychologist, 55(1), 34-43.

Diener, E., Emmons, R.A., Larson, R.J., \& Griffen, S. (1985). The satisfaction with life scale. Journal of Personality Assessment, 49(1), 71-75. 
Du Toit, M.M., Wissing, M.P., \& Putter, B. (2000, May). Constructive coping strategies: Evaluation and capacity development in students. 1st South African National Wellness Conference, Port Elizabeth.

Eriksson, M., \& Lindström, B. (2005). Validity of Antonovsky's sense of coherence scale: A systematic review. Journal of Epidemiology and Community Health, 59, 460-466.

Feldt, T., Kinnunen, U., \& Mauno, S. (2000). A mediational model of sense of coherence in the work context: A one year followup study. Journal of Organizational Behaviour, 21, 461-476.

Flannery, R.B., Perry, J.C., Penk, W.E., \& Flannery, G.J. (1994). Validating Antonovsky's sense of coherence scale. Journal of Clinical Psychology, 50(4), 575-577.

Floris, L.Y., \& Obasi, E.M. (2003). Positive psychological assessment in an increasingly diverse world. In S.J. Lopez \& C.R. Snyder (Eds.), Positive psychological assessment: A handbook of models and measures, (pp. 41-54). Washington: American Psychological Association.

Fourie, L., Rothmann, S., \& Van de Vijver, F.J.R. (2008). A model of work wellness for non-professional counsellors in South Africa. Stress and Health, 24(1), 34-47.

Foxcroft, C., \& Roodt, G. (2001). An introduction to psychological assessment in the South African context. Oxford: Oxford University Press.

Fredrickson, B.L. (2000, March 2). Cultivating positive emotions to optimize health and wellbeing. Prevention $\mathcal{E}$ Treatment, 3 , Article 0001a, 1-24. Retrieved January 23, 2003 from http:// journals.apa.org/prevention/volume3/pre0030001a.html.

Fredrickson, B.L. (2001). The role of positive emotions in positive psychology: The broaden-and-build theory of positive emotions. American Psychologist, 56(3), 218-226.

Fredrickson, B.L. (2006). Unpacking positive emotions: Investigating the seeds of human flourishing. Journal of Positive Psychology, 1(2), 57-59.

Fredrickson, B.L., \& Joiner, T. (2002). Positive emotions trigger upward spirals toward emotional wellbeing. American Psychological Society, 13(2), 172-175.

Frenz, A.W., Carey, M.P., \& Jorgensen, R.S. (1993). Psychometric evaluation of Antonovsky's sense of coherence scale. Psychological Assessment, 5(2), 145-153.

Hamad, R., Fernald, L.C.H., Karlan, D.S., \& Zinman, J. (2008). Social and economic correlates of depressive symptoms and perceived stress in South African adults. Journal of Epidemiology and Community Mental Health, 62, 538-544.

Heller, D., Watson, D., \& Ilies, R. (2004). The role of person versus situation in life satisfaction: A critical examination. Psychological Bulletin, 130, 574-600.

Hu, L., \& Bentler, P.M. (1999). Cut off criterion for fit indices in covariance structure analysis. Conventional versus new alternatives. Structural Equation Modeling, 6(1), 1-55.

Human Sciences Research Council (HSRC). (2009). The languages of South Africa. Retrieved July 07, 2009, from http://www. southafrica.info/about/people/language.htm

Kammann, N.R., \& Flett, R. (1983). Affectometer 2: A scale to measure current level of general happiness. Australian Journal of Psychology, 35(2), 259-265.

Keyes, C.L.M., Wissing, M.P., Potgieter, J., Temane, Q.M., Kruger, A., \& Van Rooy, S. (2008). Evaluation of the mental health continuum short form (MHC-SF) in Setswana speaking South Africans. Clinical Psychology and Psychotherapy (An International Journal of Theory and Practice), 15, 181-192.

Kinman, G. (2008). Work stressors, health and sense of coherence in UK academic employees. Educational Psychology, 28(7), 823-835.

Korotkov, D.L. (1994). Clarifying some issues from Korotkov (1993): A follow-up statement concerning the validity of the sense of coherence (short-form) personality measure. Personality and Individual Differences, 16(3), 499.

Lindström, B., \& Eriksson, M. (2006). Contextualizing salutogenesis and Antonovsky in public health development. Health Promotion International, 21(3), 238-244.

Lindström, B., \& Eriksson, M. (2009). The salutogenic approach to the making of HiAP/healthy public policy: Illustrated by a case study. Global Health Promotion, 16, 17-28.
Linley, P.A., \& Joseph, S. (Eds.). (2004). Positive psychology in practice. Hoboken: Wiley.

Lopez, S.J., \& Snyder, C.R. (2003). The future of positive psychological assessment: Making a difference. In S.J. Lopez \& C.R. Snyder (Eds.), Positive psychological assessment: A handbook of models and measures, (pp. 461-468). Washington DC, American Psychological Association.

Luthans, F., Luthans, K.W., \& Luthans, B.C. (2004). Positive psychological capital: Beyond human and social capital. Business Horizons, 47(1), 45-50.

Lyubomirsky, S. (2008). The how of happiness: A scientific approach to getting the life you want. New York: Penguin Press.

Lyubomirsky, S., Sheldon, K.M., \& Schade, D. (2005). Pursuing happiness: The architecture of sustainable change, Review of General Psychology, 9, 111-131.

MacCallum, R.C., Browne, M.W., \& Sugawara, H.M. (1996). Power analysis and determination of sample size for covariance structure modeling. Psychological Methods, 1, 130-149.

Marsh, H.W., Hau, K., \& Wen, Z. (2004). In search of golden rules: Comments on hypothesis testing approaches to setting cutoff values for fit indexes and dangers in over generalizing $\mathrm{Hu}$ and Bentler's findings. Structural Equation Modelling, 11, 320-341.

Oishi, S. (2006). The concept of life satisfaction across cultures: An IRT analysis. Journal of Research in Personality, 40, 411423.

Parkinson, J. (2007). Establishing a core set of national, sustainable mental health indicators in Scotland: Final report. NHS Health Scotland. Retrieved June 22, 2009, from www.healthscotland.com/uploads/documents/5798Adult $\% 20$ mental $\% 20$ health\%20indicators $\% 20-\% 2$

Paunonen, S.V., \& Ashton, M.C. (1998). The structured assessment of personality across cultures. Journal of CrossCultural Psychology, 29(1), 50-170.

Pavot, W., \& Diener, E. (1993). Review of the satisfaction with life scale. Psychological Assessment, 5(2), 164-172.

Pavot, W., \& Diener, E. (2008). The satisfaction with life scale and the emerging construct of life satisfaction. The Journal of Positive Psychology, 3(2), 137-152.

Rogler, L.H. (1989). The meaning of culturally sensitive research in mental health. American Journal of Psychiatry, 146(3), 296303.

Rothmann, S., Steyn, L.J., \& Mostert, K. (2005). Job stress, sense of coherence and work wellness in an electricity supply organisation, South African Journal of Business Management, 36(1), 1-9.

Ryan, R.M., \& Deci, E.L. (2001). On happiness and human potentials: A review of research on hedonic and eudaimonic wellbeing. Annual Review of Psychology, 52, 141-166.

Schaufeli, W.B. (2006, April). Work engagement: The emergence of an employee wellness concept. Keynote address at the South African Conference on Positive Psychology: Individual, Social and Work Wellness, 5-7 April 2006. Potchefstroom.

Seligman, M.E.P., \& Csikszentmihalyi, M. (2000). Positive psychology: An introduction. American Psychologist, 55(1), 5-14.

Smith, G.T., \& McCarthy, D.M. (1995). Methodological considerations in the refinement of clinical assessment instruments. Psychological Assessment, 7(3), 300-308.

StatSoft, Inc. (2004). Electronic statistics textbook. Tulsa StatSoft. Retrieved June 06, 2006, from http://www.statsoft.com/ textbook/stathome.html

Strumpfer, D.J.W. (1990). Salutogenesis: A new paradigm. South African Journal of Psychology, 20(4), 265-276.

Strumpfer, D.J.W. (1995). The origins of health and strength: From salutogenesis to fortigenesis. South African Journal of Psychology, 25(2), 81-89.

Strumpfer, D.J.W. (2006). The strengths perspective: Fortigenesis in adult life. Social Indicators Research, 77, 11-36.

Strumpfer, D.J.W., \& Mlonzi, E.N. (2001). Antonovsky's sense of coherence scale and job attitudes: Three studies. South African Journal of Psychology, 31(2), 30-37. 
Strumpfer, D.J.W., Viviers, M.R., \& Gouws, J.F. (1998). Antonovsky's sense of coherence scale related to negative and positive affectivity. European Journal of Personality, 12, 457-480.

Strumpfer, D.J.W., \& Wissing, M.P. (1998, September). Review of South African data on the sense of coherence scale as a measure of fortigenesis and salutogenesis. 4th Annual Congress of the Psychological Society of South Africa, 08-11 September 1998. Cape Town.

Temane, Q.M., \& Wissing, M.P. (2006). The role of subjective perceptions of health in the dynamics of context and psychological wellbeing. South African Journal of Psychology, 36(3), 564-581.

Turner, N., Barling, J., \& Zacharatos, A. (2002). Positive psychology at work. In C.R. Snyder \& S.J. Lopez (Eds.), Handbook of positive psychology (pp. 715-728). New York: Oxford University Press.

Vandenberg, R.J., \& Lance, C.E. (2000). A review and synthesis of the measurement invariance literature: Suggestions, practices and recommendations for organizational research. Organizational Research Methods, 3(1), 4-69.

Van der Colff, J.J., \& Rothmann, S. (2009). Occupational stress, sense of coherence, coping, burnout and work engagement of registered nurses in South Africa. South African Journal of Industrial Psychology / SA Tydskrif vir Bedryfsielkunde, 35(1), Art. \#423, 10 pages. DOI:10.4102/sajip.v35i1.423

Van de Vijver, T., \& Leung, K. (1997). Methods and data analysis for cross-cultural research. London: Sage.

Velicer, W.F., \& Jackson, D.N. (1990). Component analysis versus common factor analysis: Some issues in selecting an appropriate procedure. Multivariate Behavioural Research, 25(1), 1-28.
Vorster, H.H., Wissing, M.P., Venter, C.S., Kruger, H.S., Kruger, A., Malan, N.T., et al. (2000). The impact of urbanization on physical and mental health of Africans in the Northwest province of South Africa: The THUSA study. South African Journal of Science, 96, 505-514.

Waterman, A.S. (1993). Two conceptions of happiness: Contrasts of personal expressiveness (eudaimonia) and hedonic enjoyment. Journal of Personality and Social Psychology, 64, 678-691.

Waterman, A.S., Schwartz, S.J., \& Conti, R. (2008). The implications of two conceptions of happiness (hedonic enjoyment and eudaimonia) for the understanding of intrinsic motivation. Journal of Happiness Studies, 9, 41-79.

Westaway, M.S., Maritz, C., \& Golele, N.J. (2003). Empirical testing of the satisfaction with life scale: A South African pilot study. Psychological Reports, 92(2), 551-554.

Wissing, M.P., \& Temane, Q.M (2008). The structure of psychological wellbeing in cultural context: Towards a hierarchical model of psychological health. Journal of Psychology in Africa, 18(1), 45-56.

Wissing, M.P., \& Van Eeden, C. (2002). Empirical clarification of the nature of psychological wellbeing. South African Journal of Psychology, 32, 32-44.

Wissing, J.A.B., Wissing, M.P., Du Toit, M.M., \& Temane, Q.M. (2008). Psychometric properties of various scales measuring psychological wellbeing in a South African context: The FORT 1 project. Journal of Psychology in Africa, 18(4), 511-520.

Zwick, W.R., \& Velicer, W.F. (1986). Comparison of five rules for determining the number of components to retain. Psychological Bulletin, 99(3), 432-442. 